\title{
Evidence and Attestation Conflicts with Other Cases to Prove Litigation in Iran
}

\author{
Nazar Ali Payrvandi ${ }^{1} \&$ AzizAllah Fahimi ${ }^{2}$ \\ ${ }^{1}$ Department of Private Law, Graduate School, Khorramabad Branch, Islamic Azad University, Khorramabad, \\ Iran \\ ${ }^{2}$ University of Qom, Iran \\ Correspondence: AzizAllah Fahimi, University of Qom, Iran. E-mail: aziz.fahimi@yahoo.com
}

Received: February 14, 2016 Accepted: March 8, 2016 Online Published: March 31, 2016

doi:10.5539/jpl.v9n2p187 URL: http://dx.doi.org/10.5539/jpl.v9n2p187

\begin{abstract}
Conflicts of cases to prove litigation is that between the two reasons that is presented to magistrate in legal disputes have had conflicts and these two reasons are not also retractable. Cases to prove litigation in civic law and Code of Civil Procedure has been described in detail in accordance with Article of 1258 of the Civil Code of cases to prove litigation include: Confession, written documents, attestation, dominion and oath. Evidence and attestation has been emerged as the most important cases to prove litigation and other cases to prove litigation conflicts between those two together and other cases to prove litigation will be responsible for important effects and results to votes and court verdicts. In this paper we investigate the Conflict of Evidence and attestation together and other cases of proving.
\end{abstract}

Keywords: conflicts of reasons, document, attestation, code of civil procedure

\section{Introduction}

The purpose of conflict is that there is contrary between the two reasons so that are not retractable with each other; Such that two witnesses to attest in court that certain right belongs to the person of (A) and two other witnesses attest that right belongs to the person of (B). (Khazaee, 2008, 130)

Some legal experts have suggested that the conflict has three elements:

1. Existence of at least two reasons;

2. Existence of contact state between the two reasons;

3. Inconsistency in its signification for two reasons. (Ja'fari Langroodi, 1999, 262- 263)

It seems that most comprehensive definition about the conflict that encompass all kinds of conflict, is this definition "conflict is the collision of senses of two or more customary complete reasons in the forging and the composition step whether the ability to customary collect be or not be available between cases." (Hosseini, 2009, 56) conflict realizes when the validity of two reasons is certain and conflict be between their senses.

Lawyers start looking for preference aspects to resolve the conflict of reasons and try to prefer one of the reasons to another side of aspects. Thus, they resolve the conflict and lastly, if preferred aspect was not found and two reasons are in equilibrium Inevitably Moult theory is applied.

The basic rule for resolve the conflict of reasons attention to the ultimate purpose and destination of legal system is the in the branch conflict has been located in. For example, in the area of contracts attention to the common intention of entente and in conflict of legal reasons attention to the spirit of the statutory words and purpose of the legislative and in the conflict in judicial reasons attaining to the truth. Basically proof of litigation in court is required to provide of reason of the plaintiff area, in versus the invited also regularly - in self-defense or rejection position of the reasons of plaintiff, express their proving reasons. In some cases, the between reasons under citation by entente, the conflict is created and cannot resolve conflict by resorting to general principles and reasons. 


\section{The First Speech: Conflict of Document with Other Reasons}

\section{A- Conflict of document with normal document}

According to the law and legal rules, basically official document ruling on the normal document means the official document presented to the court without having to provide a reason for its accuracy, is accepted by the court, however to give effect to normal document, providing proof of its authenticity is required. The rule that the official document is preferable to the normal document, in one case, is encountered an exception, the above an exception is article 117 of Registration Act.

According to the decree of this article and vote numbered 43 dated 1972/11/01 of the General Board of the Supreme Court. If normal document of the transfer of property date is prior to the date of the official document, in this case a verdict to ratify the located deal in normal document will be rendered. However, the date of the transaction has been prior to the date of official document, of course, on the condition that in the points of registration deals are mandatory in which case the word to ratify the deal with the last date normal document will be valid. (Amraie, 2010, 126)

\section{B- Investigating the conflict of document with testimony}

Typically, border of limited testimony system is distinguished by two principles: 1) the demonstrative power of testimony in legal actions is limited to a certain amount so that only suffuses minor disputes 2) testimony in conflict with the valid documents loses its proving power. Guardian Council, contrary to the decision of the Islamic Consultative Assembly confirmed Article 1309 BC contrary to Sharia law and annulled it.

However, since the Parliament on reform in 1972/11/05 of Article 1309 retained the same text as the former; further, Guardian Council does not have the authority to invalidate directly laws passed by Islamic Consultative Assembly and can only restore it according to the constitution when they pass it to the Consultative Assembly. (Katozian 2009, 162) More accurate view is that Article 1309 BC remains valid and the terms of its impact should be studied in the provisions relating to the credibility of the witness.

\section{C- Document conflicts with the legal presumptions}

According to certain rules and principles of jurisprudence, during the conflict of one of the specific arguments with one legal presumption, reason should be preferred to circumstantial evidence because of the special meaning. This is widely accepted between Usulis and lawyers. In this regard, Article 1323 BC states: legal presumptions are valid in all the lawsuits unless there is a contrary reason.

Since reason is used absolute in given Article; therefore, any reason have the ability to overcome legal presumptions, either the aforementioned reason of judicial jurisdiction or confession or document of other reasons. In the order of reasons set forth in the Civil Code, documents are prior legal presumptions and this order is not accidental but indicates value further proof and the priority of document of over legal presumption. Therefore, if in dispute of ownership of the property, demanding claims the aforementioned property with official document and in contrast defendant relies on his seizure, in this case we should prefer demanding document to seized presumption of defendant. (Amravani, 2011, 103-104).

\section{D- Document conflict with legal presumptions}

In documents conflict with legal presumption we should consider three assumptions. The first assumption is in cases that formal document is known essential law. In such cases legal presumption lacks authority and the possibility of conflict with the official document is not imagined. The second assumption is in the cases that setting the official document is not necessary, in such cases this question arises that among legal presumptions and optional official document, which one is worth more proof? In response, it must be stated in accordance with Article $1324 \mathrm{BC}$ of legal presumption ".... it is attributable in case that dispute to the testimony of witnesses will be provable".

Therefore since according to Article 1309 of the same law, proving the unlike contents of the documents is not possible by witnesses, legal presumption is not also attributable due to testify in these cases and they cannot be superior to the documents. Third assumption is that setting the official document is not required and therefore normal document is set. In such cases, according to Articles 1324 and 1309 BC And according to mentioned description set forth in the second assumption legal jurisdiction has less probative value rather the document and therefore is defeated against the document. (Sohrabi Kashani, 2012,98)

\section{E- Conflict of document with expertise}

Due to specialty of the subject of expertise, there is no way for conflict of document with expertise. Although it is possible to widely use expertise to prove the claim of authenticity or inauthenticity of documents or also to 
prove the veracity or falsity of affairs alleged specialized in document, but it cannot confuse the conflict of expertise with the mentioned documents. As subject matter of expertise only reviews forgery, wrong, true or false of document and the subject of imperative documents is apart from that. (Amravani, 2011, 102)

Second speech: Conflict of testimony with other reasons

\section{A- Direct testimony conflicts with indirect testimony (secondhand evidence)}

If conflict is ascertained in the fully qualified direct testimony and secondhand evidence (indirect testimony) we should always prefer direct testimony on indirect testimony. (Jafari Langrodi, 2007, 360). In indirect testimony since the news are realized by achieving a subject. This increases the likelihood of false testimony and generates suspicion about the implications of the fact (Katozian, 2011, 20)

On the other hand, direct testimony, in principle all matters including the rights of God and rights of people are verifiable. This indicates less reliability of lawgiver and legislator toward secondhand evidence (indirect testimony). It should be noted that if the indirect testimony was accompanied by legal jurisdiction or the way that causes legal presumption to the judge, in this case we could prefer the set of indirect testimony and legal presumption to testimony based on the number of reasons.

\section{B- Conflict of testimony with confession}

In terms of probative qualification, jurisdiction of confession is wider than the testimony. In comparison of probative value of confession and testimony, occurrence of conflict between confession and testimony is rare and actually is beyond our expectations. While the provisions of confession must be required in dispute, provisions of testimony should be required as well. In sheer comparison of these two from the point of proof, certainly confess to testimony is superior to following reasons:

A- Although confession and testimony both are reasons, but judgments awarded to confession suggests its superiority. Confession is so strong in uncovering the truth and with making confession; the legislator has no hesitation in ruling proceedings and required the judge to issue a vote: "Whenever a person confesses to something that is a beneficiary of his side, there is no need to prove it." While there were no such absolute requirement respect to the testimony. Even regarding adequate testimony, there is no explicit provision stating that issues which has scattered thoughts to this extent.

B- Some authors also considered "local priority" of confession on the testimony among the reasons for confession superiority over testimony in Code of Civil Procedure. Although the depth of this argument is low, but certainly determining the position of talk about an object is affected by profound mental concerns of speaker and his implicit belief.

C- Article $1309 \mathrm{BC}$ has deprived the possibility to prove contrary to the provisions of official document from adequate testimony. Therefore, in the hierarchy of reasons testimony subordinates official document. This procedure is quite logical. We said that unlike witness, the official document does not lie and does not forget. It is important to note that the implied comments of legislative should suggest that official document is superior to testimony as well as its corresponding reasons. In contrast, official document never have been preferred to confession. From this major and minor reason, we can infer confession superiority over testimony can be inferred (Parsa, 2011, 233-231).

\section{D- Conflict of testimony and oath}

Practically the possibility of conflict between testimony and oath is rare, because is according to Articles 271 and 272 of code of civil procedure that is retrieved from the jurisprudential rule "testimony and oath." Therefore, if there is testimony, there will be no oath and when there is oath, there is no sign of testimony (Fahimi, 2011, 131). In the case of conflict between testimony and oath considering all of the conditions, following points contribute to resolve the conflict.

Finally, in the case that demanding is summoned with the lack of reason, and with the hope not to oath and before issuing the final decision, ask for litigation and defendant also takes an oath for the lack of demanding eligibility, although purely probative value of adequate testimony is highly superior to oath. However, it seems that the conflict between the two in this assumption should be resolved in favor of the oath. The explicit law is what is stated in provision of Article 1331 of the Civil Code "oath is the cutter of litigation and no statement which is contrary to the oath will be accepted. This advantage is not caused by these two reasons but also caused by negligence of demanding in alleging evidence (Shams 2009, 270)

\section{E- Conflict of Testimony and legal presumption}

If we are supposed to consider legal presumption as the reason, it must be mentioned a declarative - 
authentication reason in above classification. Probative qualification of legal presumption is more limited than testimony, the face of Article 1323 of the Civil Code, which has validated legal presumptions is in all litigations also is in conflict with adequate testimony and legal presumption; testimony to all of these legal presumptions is prevailed because: First, the legal presumption is "presumption" and the adequate testimony is "reason". Secondly, in presumptions the work naturally is based on the possibility and suspicion (Naseri 1967, 86-87). However, even testimony is inevitably certain, third, the testimony is direct evidence, and presumption is indirect testimony. In indirect reasons, the entrance of inference of element doubles the probability of error. As a result, the direct reason is preferred and rules over of the universal legal presumption (Katozian 2011, 175)

\section{F- Conflict of testimony and expertise}

It seems that the assumption of occurring conflict between testimony and hypothesis are of unlikely hypothesis, because the witness provides his observations, expert provides his inferences, and the type of comment that is required from them is like testimony and oath. Regarding this, description of testimony assertion region, in all of the cases especially absolute subjective affairs, is not irrespective of inference and his judgment. Testimony just introduces its tangibles and the court is responsible for inferences even its subjective inferences. However, in expertise, though expert cannot conclude from its tangibles but the subjective inference is permissible (Hayati, 2011, 458).

\section{Conclusion}

In the conflict of formal document with normal document, formal document is basically superior to normal document; nevertheless, this rule is confronted with an exceptional in a case. If the date of normal document of property transmission is superior to the date of formal document, the verdict of validity of located contract with normal document will be rendered.

In conflict of formal document with testimony of witness according to Article $1309 \mathrm{BC}$., the principle is to reject the testimony against official documents with a document, which its authenticity is defined in tribunal. However, the worst problem of jurists is to remove this Article by Guardian Council in 1988 and to validate it by Islamic Consultative Assembly in 1991.

Judge first evaluates the reasons according to the conflict of testimony with normal document because the given aspect of preference is not available in official document and in the course of superiority, one will be preferred to the other; nevertheless, the two reasons are not validated.

In the conflict of expertise with testimony of witness in affairs that are both validated, judicial proceedings of qualified adequate testimony is considered superior and the value of expertise in equivalent judicial proceedings of presumption is measured that are not tolerated to conflict with testimony.

The conflict of expertise with formal documents is not imaginable because the contrary of the contents of official document is permissible (If the litigation is not about fraud and error in the contents of the document) and validation is not expertized. The case that expertized opinion was against the contents of document and the Supreme Court judgment was based on it. Supreme Court is invalid due to the impossibility of expertise views conflict with official document.

It must be stated about the conflict of official document with the confession that this case is disputable and tractable in a hypothesis that provision of Articles 46 and 48 of the Law of Normal registration lacks the probative power in cases, and transaction about the immovable property shall be subject to the formalities required official document.

In this case, the judicial procedure in the interpretation of these provisions is leaning to one side in which only normal document will not be invoked in these cases. The assumption that confession in normal document verification and consequently approval of the transaction is done in court is able to give effect on proof of litigation of ownership. If the provisions of this confession were in conflict with official document and confession was not the detriment of third parties, it could undermine official document works and enervate it from formality.

\section{References}

Abbasi, H. K., \& Ali, S. (2012, autumn). conflict rules of evidence and fix it. Journal of jurisprudence and the history of civilization, (25).

Amrai, Y. (2010). Limits the effectiveness and credibility of official documents. Tehran: the eternal.

Amrovany, R. (2011). Conflict evidences (on the right). Tehran: Fkrsazan. 
Catoziyan, N. (2008). Property ownership. Tehran: the amount.

Catoziyan, N. (2011). General rules of contract. Tehran: Bhnshr.

Dehkhoda, A. A. (1994). Dehkhoda dictionary. Tehran: Tehran University Press.

Emami, S. H. (1983). Civil Rights Tehran: Islamia bookstore. Volume 6.

Fahimi, A. (2014). Evidences. Tehran: happiness.

Hayati, A. A. (2011). Code of Civil Procedure in the current legal order. Tehran: the amount.

Hosseini, S. M. B. (2009). Conflict of arguments. Tehran: Faith Ahmad.

Jafar Langroodi, M. J. (1999). Extensive rights in terminology. Tehran: the treasure of knowledge.

Khaza'i, S. A. (2008). Document conflicts with the testimony of Iranian law and comparative study in Jurisprudence, British and Egyptian law. Journal of Islamic Studies and Law, the ninth year, the first issue, pages 156129 .

Mohaghegh, M. (2009). Issues of Warcraft (the third book). Tehran: Publishing Center of Islamic Sciences.

Naseri, F. (1965). United Arab Emirates Iran's rights, doctoral dissertation, Faculty of Law and Political Science at Tehran University, 1965.

Parsa, M. (n. d.) comparative analysis of the probative value of confession and testimony in criminal matters and civil rights looking at America, 1390, dissertation, Criminal Law and Criminology, Tehran University.

Shams, A. (2009). Code of Civil Procedure. Tehran: Drake, the third volume.

Shams, A. (2009). Evidences (substantive and procedural rights). Tehran: Drake.

Sohrabi Kashani, E. (2012). Conflict Evidence of documents and testimony, in 2012, Islamic Azad University Central Tehran Branch, MS.

\section{Copyrights}

Copyright for this article is retained by the author(s), with first publication rights granted to the journal.

This is an open-access article distributed under the terms and conditions of the Creative Commons Attribution license (http://creativecommons.org/licenses/by/3.0/). 